\title{
Aqueduct stenosis and schizophrenia
}

\author{
ADRIANNE M REVELEY, MICHAEL A REVELEY \\ From the Institute of Psychiatry, London, UK
}

SUMMARY Three patients with hydrocephalus and aqueduct stenosis are described, who also have schizophrenia defined according to strict diagnostic criteria. There are no previous reports of such an association.

Schizophrenic symptoms in association with organic illness or injury affecting the brain are widely reported $^{12}$ but we could find no reports linking schizophrenia specifically with hydrocephalus. We were surprised therefore, when during the course of a study using computed tomographic (CT) scans of the brain to assess ventricular size in schizophrenia, ${ }^{3}$ we found three schizophrenics who had hydrocephalus and radiological evidence of stenosis of the aqueduct of Sylvius. All three were diagnosed as schizophrenia (chronic course) using the Research Diagnostic Criteria (RDC). ${ }^{4}$

\section{Case 1}

Female aged $26 \mathrm{yr}$. The second born of non-identical twins born by a forceps delivery. She had an uneventful childhood, passed the normal milestones: walked at 13 months, talked at 18 months. She was described as an over-anxious, sensitive, hard-working child, though not a very high achiever. Full scale IQ assessed as 90 . At age 16 she developed mild feelings of persecution and bad headaches, so she left school without taking any examinations. She was then investigated for suspected migraine (for which there is a strong family history), complaining of episodes of headaches, nausea, ataxia and blurred vision. She was a clerical worker for 18 months, but became anxious and upset following promotion at age 17 . She developed paranoid feelings that people were talking about her and laughing behind her back. Cars would hoot at her or flash their lights at her and she tried to persuade her family to move house to get away from the persecution. She reported special messages for her and her family coming over the TV. She had occasional auditory hallucinations, for example, a voice telling her to "grow up", affective flattening and perplexity. There was a suggestion that her psychosis had a phasic nature, withdrawn apathy alternating with incongruous giggling or extreme anxiety every 4-5 days, with perplexity and paranoid delusions remaining constant throughout. Routine skull films revealed a picture consis-

Address for reprint requests: Adrianne Reveley, Genetics Section, Institute of Psychiatry, De Crespigny Park, London SE5 8AF, UK.

Received 12 May 1982 and in revised form 11 September 1982 Accepted 1 October 1982 tent with hydrocephalus: the finding was completely unsuspected. She had a neurosurgical admission and evaluation. Her hydrocephalus was found to be stable and not thought to be directly associated with her mental status. She made a poor recovery following the first episode of psychosis, with several further admissions for paranoid delusions, but was eventually stabilised on phenothiazine medication, living in a sheltered hostel. Physical examination was unremarkable except for mild papilloedema and hyperreflexia. Visual acuity was unimpaired. There was no family history of psychiatric illness or hydrocephalus. The EEG showed moderate abnormality in the right temporo-occipital region, but she was not clinically epileptic. Her skull circumference was $56.5 \mathrm{cms}$.

\section{Case 2}

Female, aged $23 \mathrm{yr}$. She weighed $18.7 \mathrm{~kg}$ at birth, which was a forceps home delivery by a midwife. Hydrocephalus was diagnosed at two weeks and spontaneously arrested at

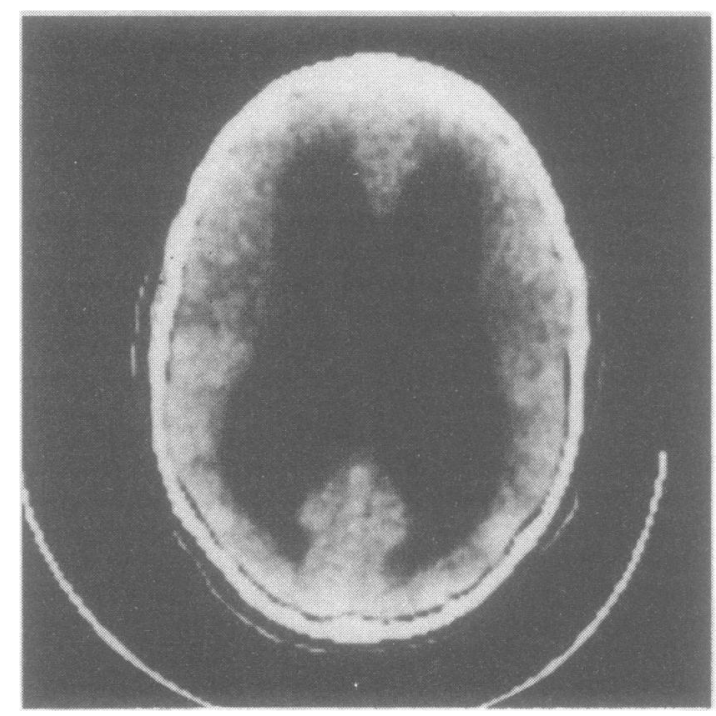

Fig 1 The body of the lateral ventricles at their largest for case 1 . 


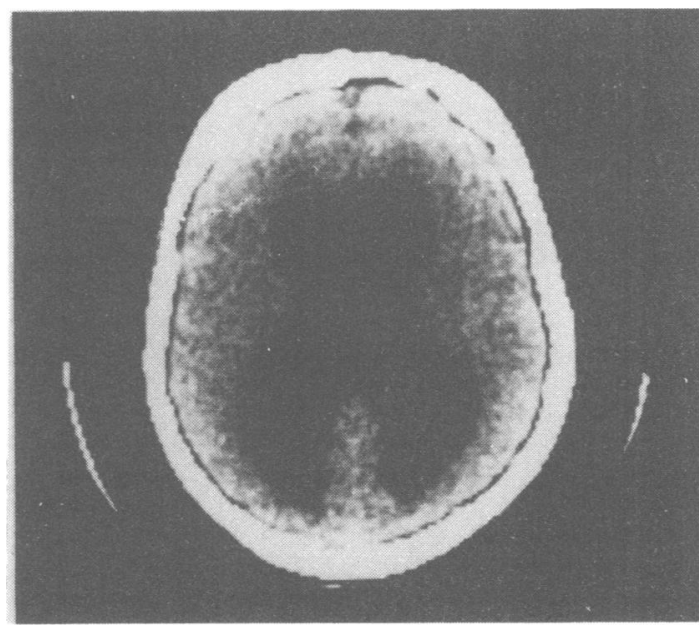

Fig 2 The body of the lateral ventricles at their largest for case 2.

age 6 months. It was not shunted. She sat and spoke at 12 months but did not walk until aged 3 years. She attended normal schools but performed poorly. Her IQ was assessed as 94 . She had a squint which was corrected at age 8 . As a child she was described as very pretty, but shy and clinging. She was subject to violent outbursts and was easily frustrated, and on this account was referred to a child guidance clinic between the ages of 11 and 13. She left school at age 16 , and for the next three years held several jobs as a shop assistant. At age 17 she made the first of many "histrionic" suicide attempts; and from then on she has been under continuous psychiatric care. She has had many inpatient stays, shown disinhibited sexual behaviour with many casual sexual affairs, excessive drinking, and brushes with the law. Over the past three years however, she has gradually become more peculiar, spending up to three hours at a time sitting absolutely motionless or with incessant repetitive shaking movements of her head and hands. These occasionally stop suddenly so that she remains "frozen" for up to a minute in an unusual position. She has developed a curious stiff, robot-like walk. She often refuses to eat or to urinate during the day only to become incontinent at night. She appears to attend to hallucinations, though she denies them. She rarely speaks except on direct questioning and then her replies are monosyllabic. Her affect is markedly flat; she evades eye contact and appears expressionless and emotionless, though she is actively suicidal unless restrained (for example, running into the street in front of a car). She has told her family that she hears voices referring to her on the TV, for example, newsreaders telling her not to eat, and she has complained of peculiar smells emanating from her body, but she will not answer direct questions relating to first rank symptoms. She requires chronic hospitalisation. Physical examination revealed a divergent squint and mild hyperreflexia. There was no family history of hydrocephalus or psychiatric illness. The EEG showed a diffuse non-specific increase in slow waves, though she was not clinically epileptic. Her skull circumference was $60 \mathrm{cms}$.
Case 3

Female, aged $60 \mathrm{yr}$. She was found to be hydrocephalic shortly after a difficult breech birth: it was not shunted. She was also treated for rickets as a child. She went to special schools and functioned in the low normal range of IQ (assessed as 80). She had various factory jobs from the age of 16 , when she left school, to age 25 . She formed two stable relationships; from the first of these she had two children. She developed epilepsy at age 27 following the death of one child in a road accident. This has been treated ever since with phenobarbitone. She first developed psychotic symptoms at the age of 35 , initially in the context of a depressive episode, but the affective features gradually became less prominent and she developed the typical picture of unremitting chronic schizophrenia. She has well encapsulated delusions, passivity feelings and hears several voices conversing among themselves about her. The voices are those of her brother and sister-in-law, who she thinks persecute her, steal her money and talk about her between themselves. They occasionally "take control" of her body in some way. For the past ten years she has remained psychotic and is a long stay inpatient. Physical examination revealed an obviously enlarged skull, slurred speech, slight ataxia, and slight spasticity and hyperreflexia of both lower limbs. There was no family history of hydrocephalus, but her father had chronic ideas of reference and had attempted suicide. The EEG showed evidence of abnormality in the left temporal region, and she was clinically epileptic though not diagnosed as having temporal lobe epilepsy. Her skull circumference was $64 \mathrm{cms}$.

\section{Method of CT scan examination}

The CT scans of these patients were examined using the Diagnostic Enhancement Package of the Maudsley Hospital CT 1010 scanner. Voxels of density -20 to +20 Hounsfield Units were assigned to CSF within the ventricu-

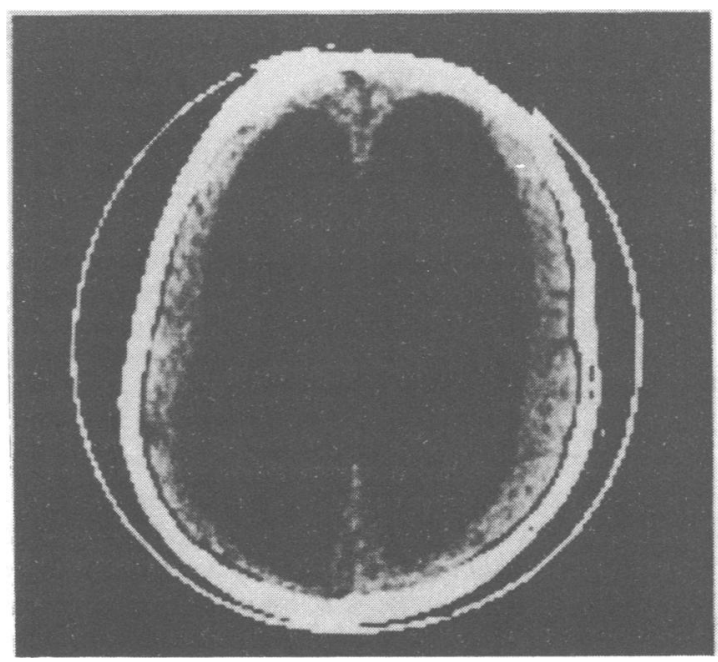

Fig 3 The body of the lateral ventricles at their largest for case 3. 
Table Ventricular volume and VBR of patients with hydrocephalus, normal controls and schizophrenics

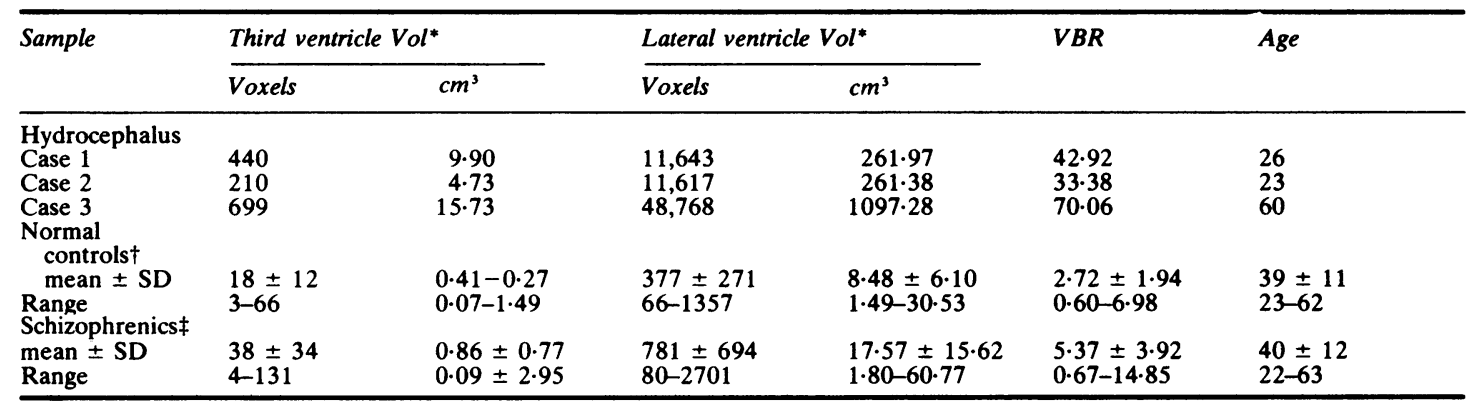

${ }^{*}$ Voxels of density -20 to +20 H.U. included as ventricle.

$+\mathrm{N}=52$.

$\ddagger N=19$.

lar area (excluding cisterns and subarachnoid space) on each "slice" visually selected by the operator. All slices showing ventricle were measured. The total number of voxels of the specified density thus provided an estimate of the total volume of the third and lateral ventricles. Ventricular/brain ratio $=$ ventricular area/brain area $\times$ 100. The ventricular volumes of our three cases, expressed as voxels and as $\mathrm{cm}^{3}(1$ voxel $=0.15 \times 0.15 \times 1.0 \mathrm{~cm}=$ $0.0225 \mathrm{~cm}^{3}$ ) are shown in the table along with normal controls and schizophrenics (using RDC criteria) from an ongoing study. The figures show the lateral ventricles at their largest for each of the cases. All the schizophrenics and the controls were blindly examined from coded floppy discs, by the same operator (MAR) who examined the scans of the hydrocephalic patients. Blind examination of the latter was not possible because of the very obvious ventricular enlargement. The test-retest reliability of measurements for both volume and VBR was 0.999. The diagnosis of aqueductal stenosis with the hydrocephalus was made in all cases on the basis of grossly enlarged lateral and third ventricles, with small fourth ventricles.

\section{Discussion}

The organic antecedents of schizophrenic symptoms are wide-ranging, from accidental injury to the brain, to generalised metabolic dysfunction. ${ }^{1}$ In this context it is reasonable that such symptoms could develop secondary to the damage caused by hydrocephalus, with or without aqueduct stenosis. Indeed, psychotic symptoms, though unreported, may perhaps occur in the setting of the characteristic mental and social deficits seen in chronic hydrocephalus (KM Lawrence, personal communication). Interestingly in the pedigree of sex-linked hydrocephalus (which is usually associated with aqueduct stenosis) reported by Jansen, ${ }^{5}$ there were three family members, not known to be hydrocephalic, who had functional psychosis.

For an association between aqueduct stenosis and schizophrenia to occur by chance must be very rare. If $0.8-1 \%$ of the population develop schizophrenia, ${ }^{6}$ congenital hydrocephalus occurs with a frequency of 0.5-1.8 per 1000 births, ${ }^{7}$ and between $11 \%$ and $43 \%$ of hydrocephalics have aqueduct stenosis, then schizophrenia and aqueduct stencsis should occur together in roughly $0.5-8.0$ individuals per million.

Typically, hydrocephalic patients show better verbal performance on intelligence tests than their abilities in other areas would lead one to expect. They may also be excessively talkative, emotionally labile, and show lack of self-reliance. ${ }^{8}$ This constellation of features has been called the "cocktail party syndrome". ${ }^{9}$ Babcock ${ }^{10}$ was one of the first to draw attention to the observation that psychosis too is quite often associated with a marked differential score on intelligence tests. These patients, like hydrocephalics, tend to score poorly on abstract reasoning in comparison to verbal ability, and this is particularly true when comparing psychotic to nonpsychotic patients with mental retardation. ${ }^{11}$

Recent evidence from the CT scans of schizophrenics has focused attention on the association between neurologic damage and schizophrenia. The ventricular enlargement which has increasingly been reported $^{31^{12-14}}$ is assumed to be a passive process following cortical atrophy, but this is not necessarily so. Weinberger and his colleagues ${ }^{15}$ found that ventricular enlargement did not correlate with indices of cortical atrophy in a series of 75 schizophrenics. They suggested that more than one pathological event could be involved, either in the cerebral cortex, or in subcortical areas. Very little is known about such possible events, however, nor is it clear how they might lead to ventricular enlargement. There have been suggestions that persistent viral infection, ${ }^{16}$ or perinatal injury ${ }^{17}$ may be involved: both of these, of course, can lead to clinically evident hydrocephalus. ${ }^{18}$ There is the possibility therefore that in some cases the ventricular enlargement seen in schizophrenia differs from hydrocephalus 
only in degree. Patients with such enlargement might be expected to demonstrate discrepant verbal scores on intelligence testing. This has not been specifically investigated, but attempts to correlate neuropsychological impairment to ventricular enlargement in schizophrenics have met with some success. 1214

The relationship of aqueduct stenosis to hydrocephalus is unclear. It is thought that at times it may be involved directly in the pathogenesis of the hydrocephalus, or it may develop as a sequel to it, perhaps resulting from compression. ${ }^{19}$ Aqueduct stenosis accompanies experimentally produced viral hydrocephalus in mice, and is there regarded as a purely secondary manifestation. ${ }^{20}$ Thus, in our patients, though they all have aqueduct stenosis, pathological involvement of the periaqueductal structures in the midbrain cannot be inferred as a primary event, or more specific in relation to the psychotic symptoms than the hydrocephalus itself, though this may be the case.

A further factor common to our cases is the presence of epileptiform features on EEG, though only Case 3 has manifest epilepsy. This is not an unexpected finding. Harrison et al, ${ }^{21}$ describing 55 cases of aqueductal stenosis in adults, found epilepsy in eight cases and EEG abnormality in 22 of the 32 who had had an EEG. But there is an increased incidence of psychosis in patients with epilepsy, ${ }^{1}$ so it is possible that in our patients the EEG findings reflect abnormalities more intimately associated with the development of the psychosis, than the hydrocephalus, even though two of them did not have clinical epilepsy.

In conclusion, a previously unsuspected association between chronic hydrocephalus with aqueduct stenosis, and the development of schizophrenia, remains a possibility. Mild cases could contribute to the ventricular enlargement reported in schizophrenia.

Dr A Reveley is supported by a Fellowship from the Wellcome Foundation. We thank all those involved in the care of these patients, the patients themselves, Dr RD Hoare, Dr KA Howlett and Professor KM Laurence. During part of this study Dr MA Reveley was a Lecturer in Psychiatry at Charing Cross Hospital Medical School.

Note: Since submitting this paper a further case of aqueduct stenosis and schizophrenia has been detected. This is a 35-year-old male who has a schizophrenic psychosis postdating (by 20 years) the development of hydrocephalus due to a midbrain tumour which blocks the aqueduct.

\section{References}

' Davison K, Bagley CR. Schizophrenia-like psychoses associated with organic disorders of the central nervous system: a review of the literature. In: Herrington RN, ed. Current Problems in Neuropsychiatry. British Journal of Psychiatry Social Publication No. 4. Ashford: Headley, 1969:113-84.

${ }^{2}$ Lishman WA. Organic Psychiatry, Oxford: Blackwell, 1978.

${ }^{3}$ Reveley AM, Reveley MA, Clifford CA, Murray RM. Cerebral ventricular size in twins discordant for schizophrenia. Lancet 1982;i:540-1.

4 Spitzer RL, Endicott J, Robins E. Research Diagnostic Criteria. Instrument No. 58. New York: New York State Psychiatric Institute, 1975.

5 Jansen J. Sex linked hydrocephalus. Dev Med Child Neurol 1975;17:633-40.

- Slater E, Cowie V. The Genetics of Mental Disorders. London: Oxford University Press, 1974:11-13.

${ }^{7}$ Howard FM, Till K, Carter CO. A family study of hydrocephalus resulting from aqueduct stenosis. $J$ Med Genet 1981;18:252-5.

${ }^{8}$ Laurence KM. Neurological and intellectual sequelae of hydrocephalus. Arch Neurol 1969;20:73-81.

9 Hadenius A-M, Hagberg B, Hyttnäf-Bensch K, Sjögren I. The natural prognosis of infantile hydrocephalus. Acta Paediatr 1962;51:117-8.

${ }^{10}$ Babcock H. An experiment in the measurement of mental deterioration. New York: Archives of Psychology, No. 1171930.

"Penrose LS. The contributions of mental deficiency research to psychiatry. $B r J$ Psychiatry 1966;112: 747-55.

${ }^{12}$ Johnstone EC, Crow TJ, Frith CD, Husband J, Kreel L. Cerebral ventricular size and cognitive impairment in chronic schizophrenia. Lancet 1976;ii:924-6.

${ }^{13}$ Weinberger DR, Fuller Torrey E. Neophytides AN, Wyatt RJ. Lateral cerebral ventricular enlargement in chronic schizophrenia. Arch Gen Psychiatry 1976; 36:735-9.

${ }^{14}$ Golden CJ, Moses JA, Zelazowski R, Graber B, Zatz LM, Horvath TB, Berger PA. Cerebral ventricular size and neuropsychological impairment in young chronic schizophrenics. Arch Gen Psychiatry 1980;37:619-23.

is Weinberger DR, Fuller Torrey E, Neophytides AN, Wyatt RJ. Structural abnormalities in the cerebral cortex of chronic schizophrenic patients. Arch Gen Psychiatry 1979;36:935-39.

${ }^{16}$ Crow TJ. Biological basis of mental disorders: the case for viral aetiology. In: Tognoni G, Bellantuono C, Lader M. eds. Epidemiological Impact of Psychotropic Drugs. Amsterdam Elsevier/North Holland Biomedical Press, 1981:33-51.

${ }^{17}$ McNeil TF, Kaij L. Obstetric factors in the development of schizophrenia: complications in the birth of preschizophrenics and in reproduction by schizophrenic parents. In: Wynne LC, Cromwell RL, Matthysse S, eds. The Nature of Schizophrenia. New York: John Wiley, 1978:401-29.

${ }^{18}$ Stagno S, Pass RF, Alford CA. Perinatal infections and 
maldevelopment. Birth Defects: Original Article Series Volume XVIII 1981;1:31-50.

${ }^{19}$ McMillan JJ, Williams B. Aqueduct stenosis. J Neurol Neurosurg Psychiatry 1977;40:521-32.

${ }^{20}$ Masters C, Alpers M, Kakulas B. Pathogenesis of reovirus Type 1 hydrocephalus in mice. Arch Neurology 1977;34:18-28.

${ }^{21}$ Harrison MJG, Robert CM, Uttley D. Benign aqueduct stenosis in adults. J Neurol Neurosurg Psychiatry 1974;37:1322-8. 